\title{
NĖŠTUMO IR GIMDYMO BAIGTYS, PASTOJUS PO PAŽENGUSIOS ENDOMETRIOZĖS OPERACIJOS
}

\author{
Saulė Kržčonavičiūtė, Vytautas Abraitis \\ Lietuvos sveikatos moksly universiteto Medicinos fakultetas
}

Raktažodžiai: endometriozè, nèštumas, gimdymas, komplikacijos.

\begin{abstract}
Santrauka
Endometriozè nustatoma 10-15 proc. vaisingo amžiaus moterų visame pasaulyje. PSO duomenimis, 40 proc. iš jų dèl šios ligos patiria nevaisingumą. Nustatyta, jog endometriozè lemia ne tik pastojimo dažnị, bet ir nèštumo bei gimdymo baigtị. Straipsnyje aprašomas pirmasis Lietuvoje pažengusios endometriozès operaciju veiksmingumo, mažinant nepageidaujamas nëštumo ir gimdymo baigtis, tyrimas. Tyrimo rezultatai: 64,06 proc. néštumų ir gimdymų buvo komplikuoti. Ketvirtadalis néštumų baigèsi persileidimu, 15,63 proc. - priešlaikiniu gimdymu. Po III stadijos endometriozès operacijos néštumo komplikacijų buvo daugiau, nei po IV stadijos operacijos $(\mathrm{p}<0,05)$. Trečdalis gimdymų baigèsi cezario pjūviu, iš jų didžioji dalis - po dirbtinio apvaisinimo IVF metodu. Daugiau cezario pjūvių atlikta gimdyvèms po IV nei po III stadijos endometriozès operacijos ( $p>0,05)$. Išvados: nėštumo komplikacijų dažnis po pažengusios endometriozès operacijos yra 40,63 procento. Daugiau néštumo komplikacijų nustatyta po III nei po IV stadijos endometriozès operacijos. Pastojus po endometriozès operacijos, didèja cezario pjūvio tikimybè. Cezario pjūvio operacijų mažiau atliekama po III nei po IV stadijos endometriozès operacijų.
\end{abstract}

\section{Ivadas}

Endometriozè - lètinè vaisingo amžiaus moterų liga, kurios pagrindiniai klinikiniai simptomai yra skausmas ir nevaisingumas [1]. Endometriozè pasireiškia, kai ị gimdos gleivinę (endometriumą) panašus audinys išplinta už gimdos ribų (dažniausiai ị mažojo dubens organus ir pilvaplèvę) ir sukelia nuo estrogeno priklausomą uždegiminę reakciją, sudaro sąaugas ar formuoja randus. Dèl šių morfologinių pakitimų keičiasi moters dubens anatomija, todèl galimi minèti bei kiti simptomai [2]. Endometriozè paveikia 1 iš 10 vaisingo amžiaus moterų, o pasaulyje šia liga serga apie 176 milijonų moterų [3]. Lietuvos higienos instituto sveikatos informacijos centro duomenimis, 2018 metais Lietuvoje buvo registruota 12417 endometriozės atvejų [4]. Endometriozès diagnozè nustatoma remiantis klinikiniais simptomais ir instrumentiniais tyrimais, o patvirtinama ịvertinus medžiagos histopatologinị mėginị [1]. Liga gali būti gydoma dviem būdais: konservatyviu ir chirurginiu, tačiau teigiama, kad visiškas endometriozès išgydymas nèra įmanomas [5]. Pacientèms, planuojančioms pastoti, rekomenduojamas chirurginis gydymas [6]. Pasaulyje daugèja mokslinių darbų, tiriančių šios ligos įtaką nepageidaujamoms nėštumo baigtims. Nustatyta, jog dažniausiai pasitaikančios nėštumo komplikacijos, siejamos su endometrioze, yra savaiminis persileidimas, priešlaikinis gimdymas, preeklampsija bei placentos pirmeiga [7-9]. Gimdymo baigtys ir komplikacijos pasaulyje nèra plačiai tyrinètos, bet yra duomenų, jog gimdyvėms, kurioms nustatyta endometriozè, dažniau atliekama cezario pjūvio operacija [10].

Tyrimo tikslas - įvertinti nèštumo ir gimdymo baigtis pastojus po pažengusios endometriozès operacijos, rezultatus palyginti su statistiniais duomenimis.

\section{Tyrimo medžiaga ir metodai}

Tyrimui atlikti gautas LSMU bioetikos centro $2020 \mathrm{~m}$. rugsèjo $15 \mathrm{~d}$. leidimas Nr. BEC-MF-05. Retrospektyvinis tyrimas atliktas Lietuvos sveikatos mokslų universiteto ligoninejje Kauno klinikose (LSMUL KK). Analizuotas 64 pacienčių, pastojusių po pažengusios endometriozès operacijos, nèštumas ir gimdymas. Gauti rezultatai palyginti su sveikų nëščiujų statistiniais duomenimis Lietuvoje ir pasaulyje. Imtị sudare LSMUL KK duomenų registre aprašytas 64 pacienčių, kurioms 2010-2015 metais buvo atliktos pažengusios endometeriozès operacijos, nèštumas ir gimdymas, ekskliuduojant néštumą pacienčių, kurios operacijos metu buvo vyresnès nei 40 metų ir (arba) kurioms buvo pašalinta gimda. Duomenų analizė atlikta naudojant programą IBM SPSS statistics 20. Skirtumai tarp požymių statistiškai reikšmingi, kai $\mathrm{p}<0,05$. 


\section{Rezultatai ir jų aptarimas}

Didžiajai daliai tiriamujų (64,06 \%) nustatyta bent viena iš šių komplikacijų: persileidimas, priešlaikinis gimdymas ir (arba) cezario pjūvio operacija. PSO duomenimis (2017), pasaulyje apie 15 proc. nëštumų ir gimdymų buvo komplikuoti [14]. Lyginant su pasauliniais statiniais duomenimis galima teigti, kad šio tyrimo rezultatai patvrtina, jog po endometriozės operacijos nèštumo ir gimdymo komplikaciju tikimybè yra didesnè.

Ketvirtadalis ( $25 \%$ ) analizuotų nèštumų nutrūko, įvykus persileidimui. Persileidimo metu něščiụjų amžiaus vidurkis buvo 29,7 metai (jauniausiai 26, vyriausiai - 35 metai). $\mathrm{Nu}$ statyta savaiminio persileidimo tikimybe 20-30 metų néščiosioms yra 8,9 proc., kuri sparčiai didejja, didejjant amžiui [12]. Remiantis statistiniais duomenimis, Lietuvoje 2015 metais nèštumų, pasibaigusių abortu (TLK-10-AM O00O03, O05, O08), atmetus dirbtinius abortus moters pageidavimu, buvo 5,1/1000 vaisingo amžiaus (15-49 metų) moterų [15]. Europoje $2017 \mathrm{~m}$. atlikto plataus tyrimo duomenimis, pacienčių, sergančių endometrioze, kurioms nebuvo atlikta operacija dèl šios būklès, persileidimo dažnis sudare 35,8 procento [16]. Kitame moksliniame darbe buvo tirtos 478 moterys ir nustatyta 29 proc. persileidimo tikimybė, sergant endometrioze [13]. Manoma, jog padidèjęs persileidimu dažnis yra siejamas su endometriozès sukeliamu uždegimu mažajame dubenyje. Teigiama, kad prasidèjęs uždegimas gali turèti įtakos sutrikusiai folikulogenezei, apvaisinimui bei implantacijai [17]. Iš šio tyrimo rezultatų palyginimo su kitais duomenimis kyla hipoteze, jog pažengusios endometriozės operacija mažina persileidimo riziką bet, ji vis tiek išlieka didesnè, nei visos nėščiųjų populiacijos.

Iš visų mokslinio darbo metu tyrinètų néštumų 15,63 proc. pasibaigè priešlaikiniu gimdymu. 30 proc. šių nèštumų baigèsi vaisiaus mirtimi gimdoje. PSO duomenimis, 2014 metais Europoje priešlaikinių gimdymų dažnis buvo 8,7 procento [17]. Kitame tyrime nustatyta, jog endometriozè priešlaikinio gimdymo dažnį didina nuo 8 iki 20 procentų [19]. Endometriozès ịtaka didesnei priešlaikinio gimdymo tikimybei aiškinama uždegiminiu procesu placentoje bei miometriume [19]. Didesnis savaiminiu persileidimu ir priešlaikinių gimdymų dažnis gali būti siejamas su dar vienu veiksniu pagalbiniu apvaisinimu. Kad endometrioze sergančios moterys galètu pastoti, neretai reikalinga dirbtinio apvaisinimo pagalba. Keliuose tyrimuose nustatyta, jog sergančiu endometrioze natūraliai pastojusiu ir dirbtinai apvaisintų moteru priešlaikinio gimdymo dažnis nesiskiria
[20, 21]. Iš mūsų tiriamų nèštumų, kurie pasibaige priešlaikiniu gimdymu, 20 proc. buvo atliktas IVF. Iš visų tyrimo metu analizuotų nèštumų, 15,63 proc. buvo pradèti apvaisinimo mégintuvèlyje pagalba (kiti pagalbinio apvaisinimo būdai nebuvo naudoti). IVF būdu ir natūraliai pradètų nèštumų baigtys buvo palygintos tarpusavyje, tačiau statistiškai reikšmingo skirtumo nenustatyta. Šio tyrimo duomenys šiuo klausimu sutapo su kitais neseniai atliktais tyrimais [20,21].

Mokslinio darbo metu ištirta, ar endometriozès stadija (III ar IV), kuriai esant atlikta operacija, turi statistiškai reikšmingos ịtakos nepalankiai nėštumo baigčiai. Išanalizavus baigčiu pasiskirstymą tarp persileidimo, priešlaikinio gimdymo ir gimdymo laiku, statistiškai reikšmingų duomenų negauta, todèl persileidimai ir priešlaikiniai gimdymai buvo sujungti ị vieną grupę ir palyginti su gimdymais laiku (1 lentelè). Gauti statistiškai reikšmingi duomenys, iš kurių galima spręsti, jog po III stadijos endometriozès operacijos dažnesnès nèštumo komplikacijos. Atsižvelgiant ị išanalizuotą mokslinę literatūrą, manyta, jog statistiškai reikšmingai daugiau něštumo komplikacijų turètų būti po IV stadijos endometriozès operacijos, nes ši stadija yra sunkesnè. Gautiems tyrimo duomenims paaiškinimo nerasta.

Duomenų registro išrašuose buvo kreipiamas dėmesys i tokias komplikacijas kaip nėčiujų hipertenzija, gestacinis diabetas, preeklampsija bei placentos pirmeiga, tačiau reikšmingų skirtumų nenustatyta. Šios komplikacijos yra kontraversiška tema daugelyje tyrimų, susijusių su endometrioze ir nèštumo komplikacijomis $[17,18]$. Tyrimo metu nustatyta, jog 40,63 proc. néštumų po endometriozès operacijos buvo komplikuoti (ivyko persileidimas arba priešlaikinis gimdymas). Japonijoje atliktame kohortiniame tyrime nustatyta, kad moterys, sergančios endometrioze (operacinis gydymas netaikomas), turi 44,8 proc. tikimybę pastojus patirti nèštumo komplikacijas [8]. Tyrimo duomenys yra panašūs ị šio mokslinio tiriamojo darbo rezultatus.

Gimdymo komplikacijoms ir baigtims analizuoti buvo naudojama ta pati imtis, atmetus nëštumus, pasibaigusius persileidimu. Iš analizuotų gimdymų 31,25 proc. baigėsi cezario pjūvio operacija. Dažniausios epikrizėse nurodytos šių chirurginių intervencijų priežastys - daugiavaisis nèš-

1 lentelė. Nèštumo baigties po III ir IV stadijos endometriozės operacijos palyginimas

\begin{tabular}{|c|c|c|c|c|}
\hline \multirow[t]{2}{*}{ Nëštumo baigtis } & \multicolumn{2}{|c|}{$\begin{array}{l}\text { Po endometriozès } \\
\text { operacijos, proc. }\end{array}$} & \multirow{2}{*}{$\begin{array}{l}\text { Iš viso, } \\
\text { proc. }\end{array}$} & \multirow[t]{2}{*}{$\chi^{2}$, lls, $\mathbf{p}$} \\
\hline & III stadijos & IV stadijos & & \\
\hline $\begin{array}{l}\text { Persileidimas ir priešlai- } \\
\text { kinis gimdymas }\end{array}$ & $53,13 *$ & 28,13 & 40,62 & \multirow{3}{*}{$\begin{array}{l}\chi^{2}=4,146,11 \mathrm{~s}=1, * \mathrm{p}=0,042, \\
\text { (lyginant su duomenimis po } \\
\text { IV endometriozès stadijos } \\
\text { operacijos) }\end{array}$} \\
\hline Gimdymas laiku & $46,87^{*}$ & 71,87 & 59,38 & \\
\hline Iš viso & 100 & 100 & 100 & \\
\hline
\end{tabular}


tumas, placentos pirmeiga bei nevaisingumas [18]. Dviem penktadaliams (40\%) gimdyvių skirtas oksitocinas, o vèliau jos buvo operuojamos dèl neprogresavusio gimdymo.

Daugiau nei ketvirtadalis $(26,67 \%)$ tyrime analizuotu gimdymų, pasibaigusių cezario pjūvio operacija, buvo pradèti IVF būdu. Sergant endometrioze ir norint pastoti neretai reikalingas dirbtinis apvaisinimas [22], todèl natūralu, jog didèjant daugiavaisio nèštumo dažniui, didèja ir cezario pjūvio operacijos tikimybė. Europos Sajungos statistikos tarnybos (Eurostat) duomenimis, Lietuvoje 2017 metais gimdymų, kurie baigèsi cezario pjūvio operacija, dažnis buvo 19,4 procento. Tai yra viena iš mažiausią cezario pjūvio tikimybę Europoje turinčių šalių [23]. Lyginant su šio mokslinio tiriamojo darbo rezultatais, po pažengusios endometriozès operacijos cezario pjūvio tikimybe Lietuvoje išauga šeštadaliu. Austrijoje atliktoje studijoje po pažengusios endometriozès operacijos nustatytas 39,2 proc. cezario pjūvio operacijų dažnis [24]. Kitame tyrime, kuriame sergančios endometrioze moterys nebuvo gydytos chirurginiu būdu, šios operacijos dažnis buvo 35 procentai (kontrolinėje grupèje - 31\%) [18].

Tyrimas parodè, jog cezario pjūvių buvo daugiau atliekama moterims, kurios gimdè po ketvirtos stadijos endometriozès operacijos $(34,62 \%)$, lyginant su gimdymais po trečios stadijos endometriozès operacijos ( $p>0,05)$. Tokių rezultatų tikètasi atsižvelgiant ị tai, kad IV stadijos endometriozè reiškia, jog mažajame dubenyje ir pilvaplèvejje yra daugiau sąaugų, komplikuojančių gimdymo veiklos vystymąsi [11].

Kitos gimdymo komplikacijos, pavyzdžiui, kraujavimas po gimdymo, tarpvietės bei makšties plyšimas, eklampsija, sepsis, embolija vaisiaus vandenimis nebuvo dažnesnès, nei visos něščiujų populiacijos.

\section{Išvados}

1. Nèštumo komplikacijų (savaiminio persileidimo arba priešlaikinio gimdymo) dažnis po pažengusios endometriozès operacijos yra 40,63 procento.

2. Daugiau néštumo komplikacijų nustatyta po III stadijos endometriozès operacijos, lyginant su rezultatais po IV stadijos endometriozès operacijos $(\mathrm{p}<0,05)$.

3. Pastojus po pažengusios endometriozès operacijos, didèja cezario pjūvio operacijos tikimybè.

4. Cezario pjūvio operacijų atliekama mažiau gimdyvèms, operuotoms dèl III stadijos endometriozès nei gimdyvèms, kurioms atliktos IV stadijos endometriozès operacijos $(\mathrm{p}>0,05)$.

\section{Literatūra}

1. Simavičius A, Bogužienė E, Kupčiūnaitė R, Černauskis K. Surgical management of endometriosis: review of the literature.
Lietuvos chirurgija, 2015;14(1):7-13.

https://doi.org/10.15388/LietChirur.2015.1.5327

2. Dunselman GAJ, Vermeulen N, Becker C, Calhaz-Jorge C, D'Hooghe T, De Bie B. ESHRE guideline: management of women with endometriosis. Human Reproduction 2014;29(3):400-12. https://doi.org/10.1093/humrep/det457

3. Adamson GD, Kennedy S, Hummelshoj L. Creating solutions in endometriosis: Global collaboration through the world endometriosis research foundation. Journal Endometriosis 2010;2(1):3-6.

https://doi.org/10.1177/228402651000200102

4. Higienos institutas. Lietuvos gyventojų sveikata ir sveikatos priežiūros įstaigų veikla. 2018.

5. Selçuk I, Bozdağ G. Recurrence of endometriosis; risk factors, mechanisms and biomarkers; review of the literature. J Turk Ger Gynecol Assoc 2013;14(2):98-103.

https://doi.org/10.5152/jtgga.2013.52385

6. Armstrong C. ACOG updates guideline on diagnosis and treatment of endometriosis. Am Fam Physician 2011;83(1):84-85.

7. Berlac JF, Hartwell D, Skovlund CW, Langhoff-Roos J, Lidegaard $\varnothing$. Endometriosis increases the risk of obstetrical and neonatal complications. Acta Obstet Gynecol Scandinavia 2017;96(6):751-60.

https://doi.org/10.1111/aogs.13111

8. Harada T, Taniguchi F, Onishi K, Kurozawa Y, Hayashi K, Harada $\mathrm{T}$, et al. Obstetrical complications in women with endometriosis: a cohort study in Japan. PLoS One 2016;11(12):e0168476. https://doi.org/10.1371/journal.pone.0168476

9. Kim S-G, Seo H-G, Kim Y-S. Primiparous singleton women with endometriosis have an increased risk of preterm birth: meta-analyses. Obstet Gynecol Science 2017;60(3):283-8.

https://doi.org/10.5468/ogs.2017.60.3.283

10. Andolf E, Thorsell M, Källén K. Caesarean section and risk for endometriosis: a prospective cohort study of Swedish registries. BJOG 2013;120(9):1061-5.

https://doi.org/10.1111/1471-0528.12236

11. Sveikatos apsaugos ministerija. Endometriozès diagnostikos ir gydymo metodika. 2012.

https://sam.lrv.lt/lt/veiklos-sritys/asmens-sveikatos-prieziura/ diagnostikos-gydymo-metodikos-ir-rekomendacijos/ diagnostikos-ir-gydymo-metodikos

12. Dugas C, Slane VH. Miscarriage. Treasure Island (FL): StatPearls 2020.

13. Santulli P, Marcellin L, Menard S, Thubert T, Khoshnood $\mathrm{B}$, Gayet $\mathrm{V}$, et al. Increased rate of spontaneous miscarriages in endometriosis-affected women. Hum Reproduction 2016;31(5):1014-23.

https://doi.org/10.1093/humrep/dew035

14. World Health Organization, UNICEF, United Nations Population Fund. Integrated management of pregnancy and childbirth. Managing complications in pregnancy and 
childbirth: a guide for midwives and doctors. WHO, 2018.

15. Lithuanian Ministry of Health. Health Information Centre of Institute of Hygiene. Lietuvos sveikatos statistika (Health Statistics of Lithuania). 2018.

16. Schwartz AS, Wölfler MM, Mitter V. Endometriosis, especially mild disease: a risk factor for mmiscarriages. Fertility and Sterility 2017.

17. WHO | New global estimates on preterm birth 2018.

18. Porpora MG, Tomao F, Ticino A, Piacenti I, Scaramuzzino S, Simonetti S, et al. Endometriosis and pregnancy: a single institution experience. Int J Environ Res Public Health 2020;17(2). https://doi.org/10.3390/ijerph17020401

19. Petraglia F, Arcuri F, de Ziegler D, Chapron C. Inflammation: a link between endometriosis and preterm birth. Fertility and Sterility 2012;98(1):36-40. https://doi.org/10.1016/j.fertnstert.2012.04.051

20. Pérez-López FR, Villagrasa-Boli P, Muñoz-Olarte M, MoreraGrau Á, Cruz-Andrés P, Hernandez AV. Association between endometriosis and preterm birth in women with spontaneous conception or using assisted reproductive technology: a systematic review and meta-analysis of cohort studies. Reproduction Science 2018;25(3):311-9. https://doi.org/10.1177/1933719117749760

21. Dong X, Liao X, Wang R, Zhang H. The impact of endometriosis on IVF/ICSI outcomes. Int J Clin Exp Pathology 2013;6(9):1911-8.

22. Vassilopoulou L, Matalliotakis M, Zervou MI, Matalliotaki C, Spandidos DA, Matalliotakis I. Endometriosis and in vitro fertilisation. Exp Ther Medicine 2018;16(2):1043-51. https://doi.org/10.3892/etm.2018.6307

23. Large differences in share of caesarean births. Europa.eu 2019. 24. Allerstorfer C, Oppelt P, Enzelsberger SH, Shamiyeh A, Schi- metta W, Shebl OJ. Delivery after operation for deeply infiltrating endometriosis. BioMed Research International 2016.

https://doi.org/10.1155/2016/8271452

\section{OUTCOMES OF PREGNANCY AND DELIVERY FOLLOWING A SURGERY OF ADVANCED ENDOMETRIOSIS \\ S. Kržčonavičiūtė, V. Abraitis}

Keywords: endometriosis, pregnancy, delivery, complications. Summary

Endometriosis affects $10-15 \%$ of fertal-age women around the world. According to $\mathrm{WHO}, 40 \%$ of these women are infertile. It is confirmed that this disease affects pregnancy rate as well as pregnancy and delivery compliaction rate. This is the first scientific research about the effectiveness of advanced endometriosis surgery in reducing unwanted outcomes of pregnancy and delivery in Lithuania. Results: $64,06 \%$ of analysed pregancies and deliveries had at least one complication. Quarter of pregnancies ended with spontaneous abortion, $15,63 \%$ - with premature labour. More pregnancy complications detected following a surgery of III stage compared IV stage endometriosis surgery. $31,25 \%$ of deliveries ended with cesarean section, most of which were obtained by IVF. Higher probablity of cesarean section was found after IV stage compared to III stage endometriosis surgery. Conclusions: pregnancy complication rate following advanced endometriosis surgery is $40,63 \%$. Higher probability of pregnancy complications obtained after III stage compared to IV stage endometriosis surgery. Probability of cesarean section delivery increases after surgery of advanced endometriosis. More cesarean sections are performed after IV stage compared to III stage endometriosis surgery.

Correspondence to: saulekrz@gmail.com

Gauta 2020-10-06 